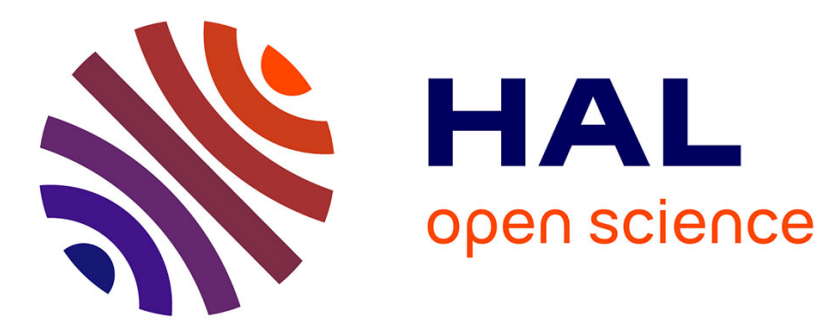

\title{
Host-pathogen interactions in the backyard of HIV-1 infection
}

Andrea Cimarelli

\section{To cite this version:}

Andrea Cimarelli. Host-pathogen interactions in the backyard of HIV-1 infection. Virologie, 2020, 24 (6), pp.349-352. 10.1684/vir.2020.0867 . hal-03249743

\section{HAL Id: hal-03249743 \\ https://hal.science/hal-03249743}

Submitted on 15 Oct 2021

HAL is a multi-disciplinary open access archive for the deposit and dissemination of scientific research documents, whether they are published or not. The documents may come from teaching and research institutions in France or abroad, or from public or private research centers.
L'archive ouverte pluridisciplinaire HAL, est destinée au dépôt et à la diffusion de documents scientifiques de niveau recherche, publiés ou non, émanant des établissements d'enseignement et de recherche français ou étrangers, des laboratoires publics ou privés. 
Host-pathogen interactions in the backyard of HIV-1 infection

Andrea CIMARELLI

Centre International de Recherche en Infectiologie (CIRI)

Univ Lyon, Inserm, U1111, Université Claude Bernard Lyon 1,

CNRS, UMR5308, ENS de Lyon,

46 Allée d'Italie,

69364 Lyon,

France.

E-mail: acimarel@ens-Iyon.fr

\section{Abstract}

The field of host-pathogen interactions studies à la loupe how cellular and viral proteins act to either oppose or facilitate viral replication. Ever since the first discovery of the concept of viral restriction in the mid half of 1900, the field has flourished and especially so in the case of HIV1 , the virus responsible of the AIDS pandemic. This editorial is meant to provide the necessary background on the field of host-pathogen interactions in HIV replication to better appreciate two reviews that appear in this issue of Virologie on two important antiviral restriction factors: APOBEC3G and TRIM5 $\alpha$.

\section{Editorial}

Independently of their name, their family and the disease they induce, all viruses are obligate intracellular parasites in that they absolutely need to enter and use the cell to multiply. In doing so, viruses have learned, and often teach us about, how to make use of specific cellular pathways needed for their replication, sometimes simply hitchhiking them and sometimes clearly re-routing them for their own purposes, as for example Coronaviruses do when they generate a novel ER-Golgi compartment devoted to the production of virion particles [1,2].

Of course, the cell is not a passive observer of the process of infection and in addition to mechanisms of defense that exist at the scale of the organism, the cell itself is capable of mounting an intrinsic mechanism of defense orchestrated by type I interferons (IFN-I). In this type of response, hundreds of genes essentially devoted to protect the cell from the infection are turned on upon the detection of the invader. Whether they are capable of ridding the cell from the virus or whether this effort is instead overcome by the virus on a number of factors from both the virus and the host side.

In this respect, the infection process can be regarded as a battlefield in which both virus and host struggle to take control over each other. The outcomes of such wars can be very different according to the virus, the animal host, as well as the level of analysis considered (the cell, the organism, or the population), as viruses can rapidly kill both cell and host (as 
Ebola infection in humans for instance), remain inside their host forever (as Epstein-Barr or Herpes Simples Viruses), or be simply removed by the organism.

In research, this battlefield is often referred to as the field of host-pathogen interactions and the implications of their study extends from pure fundamental research to pathology.

Retroviruses are a peculiar family of RNA viruses that first switch their genome from RNA to a double-strand DNA in a process called reverse transcription, and then integrate it into the host genome in a process called integration. Integration provides, at least in theory, the means for a life-long persistence of the virus inside the cell and the host. This property is rather unique in the viral world and if on one hand it provides researchers with the necessary tools to try to correct genetic diseases thanks to retroviral-mediated gene therapies [3], on the other it makes it very difficult to eliminate the integrated provirus once infection is established $[4,5]$.

Without any doubt this is at present the key problem towards a functional cure of infection by the Human Immunodeficiency type I virus (HIV-1), the causative agent of the Acquired Immunodeficiency Syndrome (AIDS) pandemic worldwide and by large the most studied member of the Retroviridae family.

Recent events clearly highlight the fact that viruses sometimes do jump from one animal species to the other and sometimes into the human population. While the current epidemic of Coronavirus is a recent reminder that this occurs, HIV-1 is also a typical example of successful viral transmission from animals to humans. In this case, simian viruses that naturally infected primates, gradually acquired changes in viral proteins (adaptations) that allowed them to cope with the cytoplasmic environment of human cells, hence allowing them to replicate in a new animal host (humans) [6].

\section{A snapshot of the viral life cycle of HIV-1}

The life cycle of HIV-1, and of Retroviruses in general, is classically divided into early and late phases, with integration of the viral genome into the host's marking the separation between the two (Figure 1). After the engagement of the viral envelope protein (Env) to the cellular receptor and co-receptor at the cell surface (CD4 and CXCR4 or CCR5), the viral and cellular membrane fuse with each other and the viral content penetrates inside the cell cytoplasm. At this point, the viral genome is a single-strand RNA molecule present in two copies and protected within a higher order protein complex called either viral nucleoprotein complex (VNP), viral core or viral capsids. In isolated virion particles VNPs possess a distinctive hexameric structure composed of the viral protein capsid (CA) [7]. However, once inside the cell, the structure of VNCs is more challenging to observe and by itself this topic alone would deserve an entirely dedicate set of reviews.

Do VNCs remain intact while reaching the nuclear pore and perhaps even through them as recent data seems to suggest, or do they undergo structural changes in the cytoplasm that facilitate the reverse transcription of the viral RNA genome into DNA? These questions remain for the moment open.

However, it is a fact that during the early phases of the viral life cycle, the viral genome is retro-transcribed in a double-stranded DNA form that finds its way and is integrated into the host genome. Following integration, viral RNAs are transcribed from the viral promoter (the 
long terminal repeat, LTR) giving raise ultimately to novel structural proteins (Gag and GagPro-Pol and Env) that assemble into new virion particles.

During this process, the virus uses a plethora of cellular proteins to its advantage (cellular cofactors) and similarly encounters several cellular proteins that inhibit it more or less effectively. These proteins, most of which, albeit not all, are regulated by interferon, are referred to as antiviral restriction factors and Figure 1 presents a small selection of wellestablished ones. As the field advances, a number of proteins with inhibitory activities are being highlighted on a regular basis that act at basically all steps of the viral life cycle.

In some cases, the action of these viral proteins would be so strong that HIV-1 devoted individual proteins to their neutralization. These proteins are called viral antagonists and are also mentioned in Figure 1.

In the present issue of Virologie, two reviews will deal with two restriction factors of key importance in HIV-1 replication: the Apolipoprotein B Editing Complex $3 \mathrm{G}$ protein (APOBEC3G) that acts during reverse transcription and is specifically counteracted by the Viral Infectivity protein (Vif) [8] and the Tripartite Motif protein $5 \alpha$, which acts against viral capsids during the early phases of infection [9]. In this context, it seems appropriate to provide an historical perspective that led directly or indirectly to their discovery.

\section{A brief historical overview of the birth of the concept of restriction (and of the concept of restriction factors)}

In 1957, Charlotte Friend first described the isolation of a Retrovirus that caused leukemia (so named the Friend Leukemia virus) in Swiss mice, but not in other strains of mice. Genetic crossing between different mouse strains led to the notion that the susceptibility or resistance of a given mouse strain to viral infection was essentially genetic and thus determined by chromosome-encoded differences [10]. In 1967, Frank Lily added to the concept from the virus standpoint when he described the isolation of a mutant strain of the Friend Leukemia Virus that had acquired the capacity to infect otherwise resistant mice strains, demonstrating that the virus was not a simple bystander either [11].

What caused the resistance of specific mice strains to infection and how did the virus mutate to acquire the novel ability to infect them?

To shorten a long walk that was concluded in 1996 with the identification of the gene responsible for this restriction [12], mice code different forms (alleles) of a gag gene (the Friend-virus susceptibility gene $1, \mathrm{Fv} 1$ ). This gene is in fact an human endogenous retrovirus (HERV-L, an ancient retrovirus that is permanently present in the chromosome of mice) and its protein product, Fv1, interferes with incoming VNCs (also made of one Gag product, the capsid). It becomes now clear why mice ended up retaining an ancient retrovirus in their genome: it made them resistant to certain viral infections. At the scale of the population, the existence of different Fv1 variants is also advantageous as it implies a population-level heterogeneity with respect to different related viruses. On the other hand, the virus is not a passive spectator either and can mutate its Capsid protein to avoid Fv1 restriction. 
The advent of more modern techniques and the use of cell hybrids in which one resistant cell can be fused to a susceptible one prior to viral infection, substantially eased the burden of work with respect to genetic crossing of animals. However, the conceptual framework that led to the very notion of genetic determinants of resistance and susceptibility was established in this manner. A similar approach is still largely used to identify novel antiviral factors, for instance by comparing wild-type viruses to mutant ones that can or no longer can replicate in certain cells, or by comparing the transcriptional program of cells that support high levels of viral replication to those that do not.

In the following pages of this number of Virologie, two reviews will describe in deep detail the peculiar behavior of two prototype of restriction factors: the APOBEC3 family and T5 $\alpha[8,9]$.

\section{Figure 1. Schematic representation of the HIV-1 life cycle}

The early phases of infection are comprised between the attachment of the virus to the cell and the integration of its genome into the host's, while the late phases start from the transcription of the viral genome to the release of novel virion particles. In the insets, APOBEC3G that found its way into virion particles during the assembly phase, becomes activated when the particle enters a new cell and reverse transcription begins by attacking the viral genome in its transient sinlge-strand DNA form. Vif, its viral antagonist, protects the virus by degrading Vif in virion-producing cells. At the same time, viral cores are sampled and attacked by TRIM5 $\alpha$ that binds VNCs. HIV-1 can protect itself by decorating its capsid with the cellular protein CyclophilinA (CypA) [13]. The cellular protein tetherin/BST-2 impairs the release of virion particles from infected cells $[14,15]$. Its viral antagonist the viral protein $U$ (Vpu) redirects it/degrades it away from the virion particle. The Serine Incorporator (SERINC5) is a membrane-associated protein that is incorporated into virions where it interferes with their ability to fuse with new cells. The negative effector (Nef) opposes this $[16,17]$. VNCs= viral nucleoprotein complexes; $\mathrm{NC}=$ nucleocapsid; $\mathrm{CA}=$ capsid. White and blue represent $\mathrm{CA}$ hexamers and pentamers, respectively.

\section{Bibliography}

1. Tooze, J., Tooze, S. A. \& Fuller, S. D. Sorting of progeny coronavirus from condensed secretory proteins at the exit from the trans-Golgi network of AtT20 cells. The Journal of Cell Biology 105, 1215-1226 (1987).

2. Krijnse-Locker, J., Ericsson, M., Rottier, P. J. \& Griffiths, G. Characterization of the budding compartment of mouse hepatitis virus: evidence that transport from the RER to the Golgi complex requires only one vesicular transport step. The Journal of Cell Biology 124, 55-70 (1994).

3. Durand, S. \& Cimarelli, A. The inside out of lentiviral vectors. Viruses 3, 132-159 (2011).

4. Dufour, C., Gantner, P., Fromentin, R. \& Chomont, N. The multifaceted nature of HIV latency. The Journal of Clinical Investigation 130, 3381-3390 (2020). 
5. Margolis, D. M. et al. Curing HIV: Seeking to Target and Clear Persistent Infection. Cell 181, 189206 (2020).

6. Sauter, D. \& Kirchhoff, F. Key Viral Adaptations Preceding the AIDS Pandemic. Cell Host \& Microbe 25, 27-38 (2019).

7. Fernandez, J. \& Arhel, N. J. HIV capsid and productive infection: taking steps in the right direction. Virologie (Montrouge, France) 24, 88-98 (2020).

8. Verriez C, Marquet R, Paillart JC, Stupfler B. Les APOBEC: histoire d'une famille de protéines antivirales et mutagènes. Virologie (Montrouge) $2020 ; 24$ (6) : $x$-xx.

9. Khalfi S, Mérindol N, Berthoux L. Fonctions cellulaires et antivirales de TRIM5alpha. Virologie (Montrouge) $2020 ; 24$ (6) : y-yy.

10. Friend, C. Cell-free transmission in adult Swiss mice of a disease having the character of a leukemia. The Journal of Experimental Medicine 105, 307-318 (1957).

11. Lilly, F. Susceptibility to two strains of Friend leukemia virus in mice. Science (New York, N.Y.) 155, 461-462 (1967)

12. Best, S., Le Tissier, P., Towers, G. \& Stoye, J. P. Positional cloning of the mouse retrovirus restriction gene Fv1. Nature 382, 826-829 (1996).

13. Kim, K. et al. Cyclophilin A protects HIV-1 from restriction by human TRIM5 $\alpha$. Nat Microbiol 4, 2044-2051 (2019).

14. Van Damme, N. et al. The interferon-induced protein BST-2 restricts HIV-1 release and is downregulated from the cell surface by the viral Vpu protein. Cell Host \& Microbe 3, 245-252 (2008).

15. Neil, S. J. D., Zang, T. \& Bieniasz, P. D. Tetherin inhibits retrovirus release and is antagonized by HIV-1 Vpu. Nature 451, 425-430 (2008).

16. Rosa, A. et al. HIV-1 Nef promotes infection by excluding SERINC5 from virion incorporation. Nature 526, 212-217 (2015).

17. Usami, Y., Wu, Y. \& Göttlinger, H. G. SERINC3 and SERINC5 restrict HIV-1 infectivity and are counteracted by Nef. Nature 526, 218-223 (2015). 


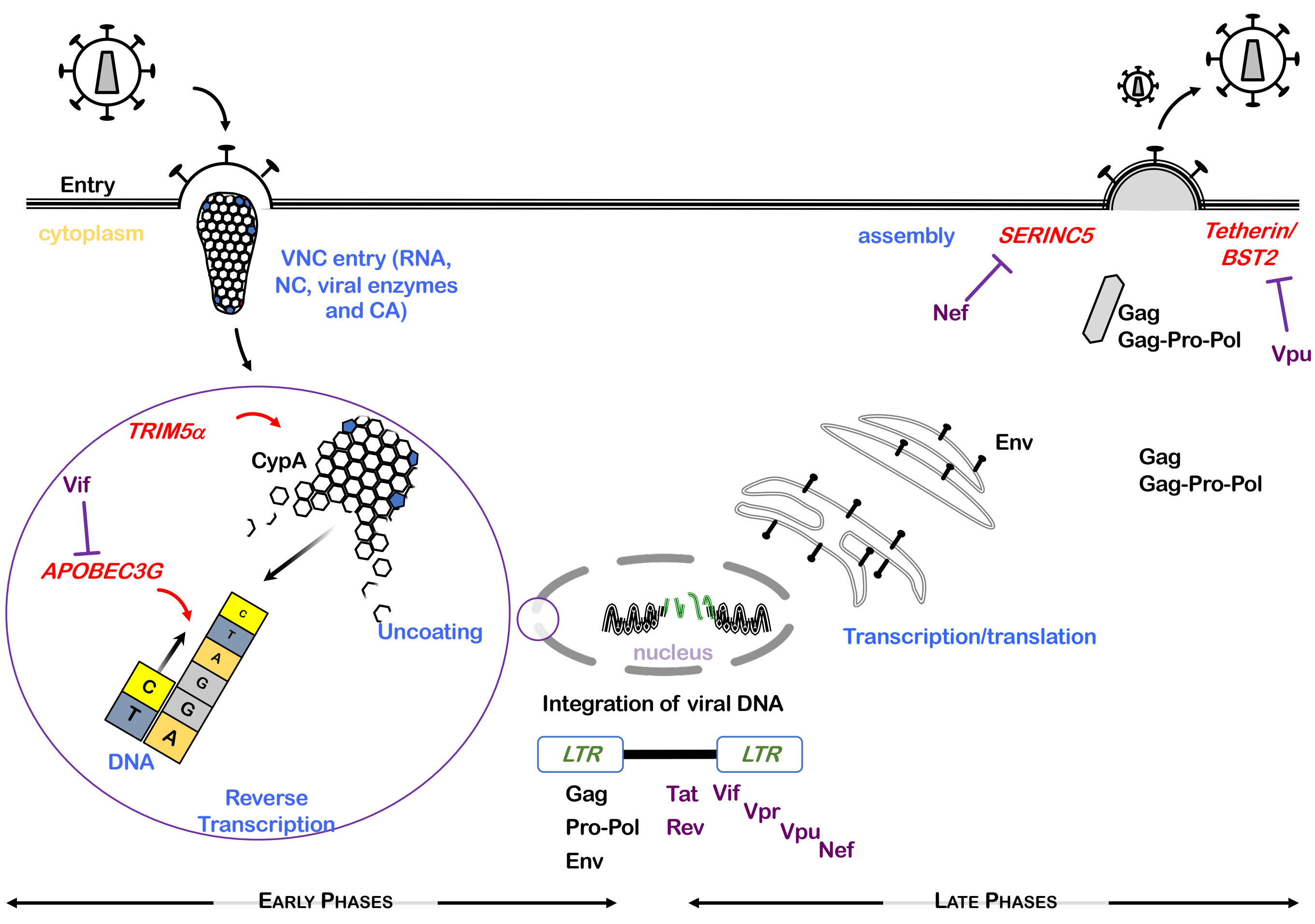

